\title{
DESENVOLVIMENTO DE UM EQUIPAMENTO INTELIGENTE: BASTÃO DETECTOR DE ALTA TENSÃO
}

\author{
Eloísa Soares de Aquino (UFCG/CDSA) eloisaaquino11@ hotmail.com \\ Lucielly Cristina da Silva (UFCG/CDSA) luciellycristina082@gmail.com
}

\section{Resumo}

O mercado atual vivencia uma fase de constantes mudanças devido às inovações tecnológicas, que vem tomando um grande espaço dentro da indústria. Assim a fabricação e melhoria dos produtos têm por obrigação suprir as exigências do marcado acompanhando seu avanço. Neste sentido realiza-se a fabricação de um equipamento inteligente, um bastão que detecta alta tensão sem a necessidade do toque do colaborador. A metodologia aplicada foi a pesquisa bibliográfica, análise experimental e a confecção do equipamento. $O$ resultado do experimento atingiu o objetivo do artigo, que consiste na criação do bastão. Observou-se que com a eficiência do equipamento torna-se possível detectar corrente elétrica sem efetuar o toque, informando ao colaborador que o manuseia a presença ou ausência da eletricidade. Ao fim, concluiu-se que a criação do bastão como um equipamento inteligente traz uma contribuição para a segurança no trabalho realizado com altas tensões.

Palavras - chaves: Equipamento inteligente, Alta tensão, NR10.

\section{Introdução}

O crescente número de acidentes e doenças relacionadas ao ambiente de trabalho, desperta nas empresas a necessidade de investir em segurança do trabalho. Visando reduzir os acidentes de trabalho e as doenças ocupacionais e proteger a integridade e capacidade de trabalho do funcionário.

As atividades que envolvem eletricidade são extremamente perigosas. De acordo com a Associação Brasileira de Conscientização para os Perigos da Eletricidade (Abracopel), no ano de 2017 houve 627 mortes por choque elétrico. Por isso é importante que o funcionário seja capacitado e utilize o equipamento adequado para realizar suas funções. 
Uma das medidas utilizadas para prevenção de acidentes é o uso de equipamentos de proteção individual (EPI). É dever de o empregador disponibilizar os EPI's e fornecer as devidas orientações de uso. E ao empregado, cabe a obrigação de utilizá-los corretamente.

Levando em consideração a importância dos EPI's e o crescimento da tecnologia dentro da indústria, é possível criar EPI's ainda mais eficientes. Um equipamento ainda mais competente capaz de traduzir informações para quem o manuseia, através de avisos ou sinais, prevenindo ainda mais os possíveis acidentes.

\section{Referencial teórico}

\subsection{Segurança do trabalho}

Segundo PEIXOTO (2011), a segurança do trabalho pode ser entendida como o conjunto de medidas adotadas, visando minimizar os acidentes de trabalho, doenças ocupacionais, bem como proteger a integridade e a capacidade de trabalho das pessoas envolvidas. É praticada pela conscientização de empregadores e empregados em relação aos seus direitos e deveres e deve ser praticada no trabalho, na rua, em casa, em todo lugar e em qualquer momento.

De acordo com PEIXOTO (2011), A Segurança do Trabalho é definida por normas e leis. No Brasil a Legislação de Segurança do Trabalho baseia-se na Constituição Federal, na Consolidação das Leis do Trabalho (CLT), nas Normas Regulamentadoras e em outras leis complementares como portarias, decretos e convenções internacionais da Organização Internacional do Trabalho (OIT) e Organização Mundial da Saúde (OMS).

\subsection{Acidente de trabalho}

Segundo PEIXOTO (2011), acidente de trabalho é aquele que ocorre durante o exercício do trabalho, provocando lesão corporal, perturbação funcional, doença que cause a morte, perda ou redução permanente ou temporária de condições de trabalho.

São considerados acidentes do trabalho, agressão física, ato de sabotagem, brincadeiras, conflitos, ato de imprudência, negligência ou imperícia, desabamento, inundação e incêndio.

$\mathrm{O}$ acidente de trabalho pode ser dividido em:

- Acidente típico: É consagrado no meio jurídico como definição de infortúnio do trabalho originado por causa violenta, como batidas, quedas, choques, entre outros. 
- Doença do trabalho: É a alteração orgânica que se desenvolve em consequência da atividade exercida pelo trabalhador o qual esteja exposto a agentes ambientais como ruído, calor, gases, entre outros.

- Incidente: Quando ocorre um acidente sem danos.

PEIXOTO (2011) afirma ainda, que há duas causas de acidentes de trabalho:

- Ato inseguro: É o que depende do trabalhador, que de maneira consciente ou não, provoca dano a si mesmo, aos companheiros e às máquinas e equipamentos, como agir sem permissão, improvisar, não utilizar equipamento de proteção.

- Condições inseguras: São as condições presentes no ambiente de trabalho que comprometem a integridade física ou a saúde do trabalhador, como defeitos em máquinas, falta de espaço, instalações elétricas, entre outras.

\subsubsection{Acidentes de trabalho com eletricidade}

Segundo LOUREIRO (2016), para trabalhar com eletricidade é necessário adotar uma série de medidas preventivas para se proteger contra choques e explosões elétricas. As atividades profissionais que envolvem eletricidade possuem uma alta periculosidade e um grande número de acidentes fatais.

LOUREIRO (2016) afirma que as principais causas de acidentes com eletricidade são:

- Falta de treinamento técnico: É de extrema importância capacitar os colaboradores e deixá-los sempre cientes das normas regulamentadoras, promover debates e treinamentos. A falta de treinamento é um dos principais motivos para que ocorra um acidente.

- Não seguir os procedimentos exigidos: Quando há falta de treinamento, o colaborador não irá executar suas funções cumprindo todos os requisitos recomendados.

- Falta de comunicação: É importante que haja comunicação, discussão e orientação entre os colaboradores para que a falta da mesma não ocasione acidentes de trabalho.

- Distrações: Como o trabalho com eletricidade é de alta periculosidade é necessário que haja o máximo de cautela e atenção.

- Não utilizar os EPI's de forma correta: É obrigatório que a empresa forneça aos seus colaboradores todos os equipamentos necessários para que possam realizar suas funções de forma mais segura. É obrigatório, também, que os colaboradores façam uso desses equipamentos. 
Para que todas as medidas de segurança sejam adotadas corretamente pelos colaboradores, foi criada a Norma Regulamentadora 10 (NR 10), que regulamenta a atuação dos profissionais em atividades que envolva eletricidade e determina as condições básicas para garantir a saúde e segurança dos colaboradores.

\subsection{Processo de Desenvolvimento do Produto (PDP)}

De acordo com TAVEIRA (2012), o Desenvolvimento de Produto é o processo em que uma organização transforma as informações obtidas no mercado e as possibilidades tecnológicas em informações favoráveis para a fabricação de um produto.

Rozenfeld (2006) afirma que o Processo de Desenvolvimento de Produtos (PDP) pode ser definido um conjunto de atividades por meio das quais se busca, a partir das necessidades do mercado e das possibilidades e restrições tecnológicas, e considerando as estratégias competitivas e de produto da empresa, chegar às especificações de projeto de um produto e de seu processo de produção, para que a manufatura seja capaz de produzi-lo. Ainda, o desenvolvimento de produto envolve o acompanhamento do produto após o lançamento, bem como o planejamento da descontinuidade do produto no mercado incorporando estes conceitos na especificação do projeto atendendo assim, todas as necessidades do produto ao longo do seu ciclo de vida.

TAKAHASHI \& TAKAHASHI (2007) afirma que os produtos precisam passar por uma série de fases de desenvolvimento para que possam ser confeccionados. As fases são:

- Fase 0: Avaliação de conceito: Fase em que é necessário avaliar as oportunidades de produto, buscando-se informações sobre as necessidades de mercado, as possibilidades tecnológicas e a viabilidade econômica para que possa ser iniciado o processo de desenvolvimento do produto.

- Fase 1: Planejamento e especificação: Definir com clareza o produto, identificar as vantagens competitivas, esclarecer a funcionalidade, especificar os custos e determinar a viabilidade de desenvolvimento mais detalhado.

- Fase 2: Desenvolvimento: Desenvolver o produto propriamente dito, baseando-se nas decisões aprovadas na Fase 1. Fase em que acontece o detalhamento do projeto e as atividades que serão desenvolvidas.

- Fase 3: Teste e avaliação: Realizar o teste final e preparar a produção e o lançamento do produto. 
- Fase 4: Liberação do produto: Verificar se a produção, o marketing de lançamento, o sistema de distribuição e o suporte estão preparados para iniciar as atividades.

\subsection{Norma Regulamentadora 10 - Instalações e serviços em eletricidade}

De acordo com CAMISASSA (2015), o índice de acidentes envolvendo energia elétrica aumentou de forma significativa mostrando a gravidade das condições de segurança e saúde existentes nas atividades e serviços no setor energético.

Segundo a Portaria GM n. 598 (2004), esta Norma Regulamentadora - NR 10 estabelece os requisitos e condições mínimas objetivando a implementação de medidas de controle e sistemas preventivos, de forma a garantir a segurança e a saúde dos trabalhadores que, direta ou indiretamente, interajam em instalações elétricas e serviços com eletricidade.

CAMISASSA (2015), afirma que após a publicação da Portaria 598 a NR ganhou nova redação, foram incluídas importantes determinações como a proibição de trabalho individual em atividades com alta-tensão ou no sistema elétrico de potência e a obrigatoriedade de elaboração do Prontuário de Instalações Elétricas e do Manual descritivo dos itens de segurança nas instalações. Também foi detalhado o perfil do trabalhador habilitado, qualificado, capacitado e autorizado, entre outras importantes alterações.

Para o campo de aplicação da NR 10, CAMISASSA (2015) refere-se às fases de geração, transmissão, distribuição e consumo, incluindo as etapas de projeto, construção, montagem, operação, manutenção das instalações elétricas e quaisquer trabalhos realizados nas suas proximidades:

- Fase de geração: A energia elétrica pode ser gerada a partir de várias fontes, sejam elas renováveis (sol, vento, água) ou não renováveis, também chamadas de esgotáveis (biomassa e energia nuclear). A fase de geração corresponde ao conjunto de sistemas geradores como usinas hidrelétricas, termelétricas, eólicas e nucleares.

- Fase de transmissão: Geralmente, as usinas são construídas longe dos centros consumidores, sendo necessária a sua transmissão. Isso ocorre através de uma rede de transmissão composta por cabos aéreos, transformadores, sistemas isolantes e subestações. Nessa fase a energia elétrica é transmitida em alta-tensão a fim de evitar a perda excessiva de energia.

- Fase de distribuição: Ao chegar aos centros de consumo, essa energia precisa ser distribuída a todos os consumidores, devendo ser convertida em um nível de tensão no 
qual os equipamentos elétricos operam (110V ou 220V). Essa é a função dos sistemas de distribuição. Uma vez disponibilizada nas tomadas das residências, escritórios, empresas e demais unidades consumidoras, a energia elétrica poderá ser finalmente consumida, o que ocorre quando são ligadas as máquinas, equipamentos ou aparelhos eletroeletrônicos.

De acordo com a Portaria GM n. ${ }^{\circ} 598$ (2004), a NR10 alcança as etapas de:

- Projeto: planejamento, levantamentos, medições;

- Construção: preparação, montagens e instalações;

- Operação: supervisão, controles, ação e acompanhamentos;

- Manutenção: diagnóstico, reparação, substituição de partes e peças, e testes.

CAMISASSA (2015) frisa a importância de também compreender o que é "zona controlada": O risco na execução de serviços em instalações elétricas será maior ou menor dependendo se o trabalhador está mais próximo ou mais afastado do ponto energizado. Para isso, a NR10 nos apresenta os conceitos de "zona controlada" e "zona de risco":

- Zona Controlada: entorno de parte condutora energizada, não segregada, acessível, de dimensões estabelecidas de acordo com o nível de tensão, cuja aproximação só é permitida a profissionais autorizados.

- Zona de Risco: entorno de parte condutora energizada, não segregada, acessível inclusive acidentalmente, de dimensões estabelecidas de acordo com o nível de tensão, cuja aproximação só é permitida a profissionais autorizados e com a adoção de técnicas e instrumentos apropriados de trabalho.

Tais zonas correspondem à distância radial medida a partir do ponto energizado (PE), de forma que quanto maior a faixa de tensão nominal da instalação elétrica, maior será o raio que delimita a respectiva zona.

\subsection{Equipamento de proteção individual (EPI)}

Segundo et al. LOURENÇO, a principal medida de proteção ao trabalhador é a utilização de EPI's, e entende-se por EPI os equipamentos ou dispositivos de uso individual e que possuam CA (Certificado de Aprovação) e CRF (Certificado de Registro do Fabricante), emitido pelo MTE (Ministério do Trabalho e Emprego), utilizados pelo trabalhador para a sua própria proteção contra a exposição aos riscos durante a realização de suas atividades laborais.

Dentre os principais EPI's destacam-se:

- Capacete de proteção tipo aba frontal utilizado para proteção da cabeça; 
- Calçado de segurança utilizado para proteção dos pés contra torção, escoriações, derrapagens e umidade;

- Óculos de proteção para os olhos contra impactos mecânicos, partículas volantes e raios ultravioletas;

- Luva isolante de borracha utilizada para a proteção contra choque elétrico;

- Cinto de segurança tipo pára-quedista deve ser utilizado em atividades com mais de 2 $\mathrm{m}$ de altura do piso, e sempre que haja risco de queda;

- Vestimentas de trabalho para proteção do corpo do trabalhador contra queimaduras e/ou explosões provenientes de acidentes com choque ou arco elétrico.

Segundo Segurança e Medicina do Trabalho (2008, p.73), citado por MARCOS PEREIRA DA SILVA, o uso de EPI está previsto na legislação trabalhista, ou seja, a Consolidação das Leis do Trabalho (CLT).

Ainda de acordo com Segurança e Medicina do Trabalho (2008, p.73), também citado por MARCOS PERERIRA DA SILVA, cabe ao empregador quanto ao EPI, adquirir o adequado ao risco de cada atividade, exigir seu uso, fornecer ao trabalhador somente o aprovado pelo órgão nacional competente, orientar e treinar o trabalhador sobre o uso adequado guarda e conservação.

Segundo Lacombe apud Hasse (2008) citado por SILVA, em geral os funcionários, quando não são bem instruídos e treinados no uso do EPI, afirmam que os riscos a que se expõem são pequenos, que já estão acostumados e sabem como evitar o perigo e que o uso de EPIs é incômodo e limitam os movimentos.

De acordo com SEGURANÇA E MEDICINA DO TRABALHO (2008, p.74) citado por SILVA, cabe ao empregado quanto ao EPI, usar utilizando-o apenas para finalidade a que se destina responsabilizar-se pela guarda e conservação, comunicar qualquer alteração que o torne impróprio para o uso, cumprir as determinações do empregador sobre o uso adequado.

Silva relata que para orientar e fiscalizar o dia a dia dos funcionários, ajudar na conscientização e prevenção, a empresa conta com a ajuda do técnico de segurança. Ele tem a responsabilidade e também o poder para tomar as ações necessárias em caso de não conformidade com o processo. Deve estar envolvido no processo, buscando levantar pontos que possam trazer riscos de acidentes e tomando as ações necessárias para minimizar a incidência desses. Nas organizações esse papel não é bem visto pela maioria dos funcionários, 
ainda existe muita resistência quanto ao trabalho desenvolvido pelos técnicos de segurança no trabalho.

\section{Materiais e métodos}

Para a confecção do equipamento inteligente utilizou-se um sensor para detectar correntes de alta tensão através de informações sonoras e visuais.

A pesquisa foi realizada na cidade de Sumé - PB, elaborada de forma bibliográfica e qualitativa, sendo desempenhada a partir de registros científicos disponíveis a exames. Refere-se a uma análise experimental, visto que o objetivo de estudo foi determinado e selecionada possíveis variáveis com intuito de chegar à meta estabelecida que consiste em confeccionar um equipamento inteligente.

Para a confecção do bastão detector de alta tensão utilizou os seguintes materiais:

- Fita isolante (Figura 1)

- Sensor 74HC4D (Figura 2);

- Cabo coaxial para antena de TV (Figura 3);

- Pilha palito AAA (Figura 4).

Figura 1

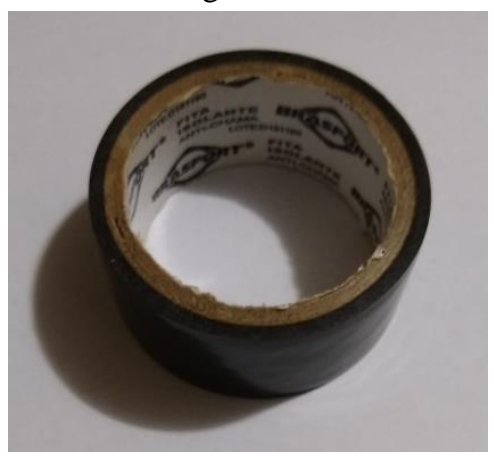

Fonte: Autoria própria (2018)

Figura 3

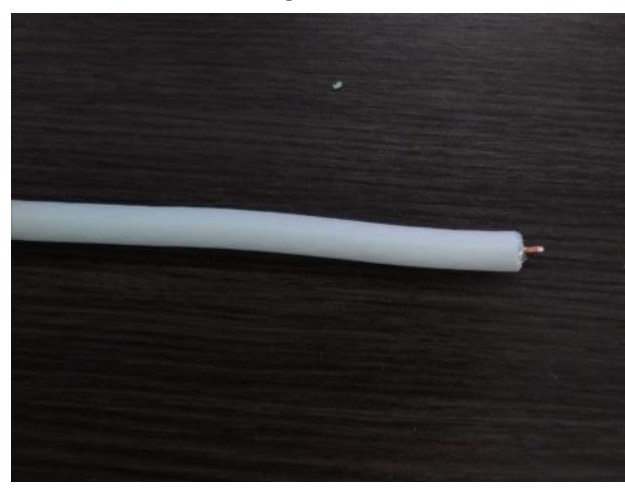

Fonte: Autoria própria (2018)
Figura 2

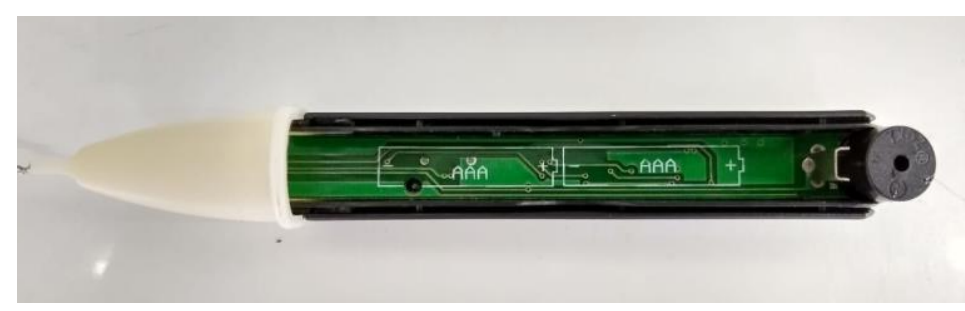

Fonte: Autoria própria (2018)
Figura 4

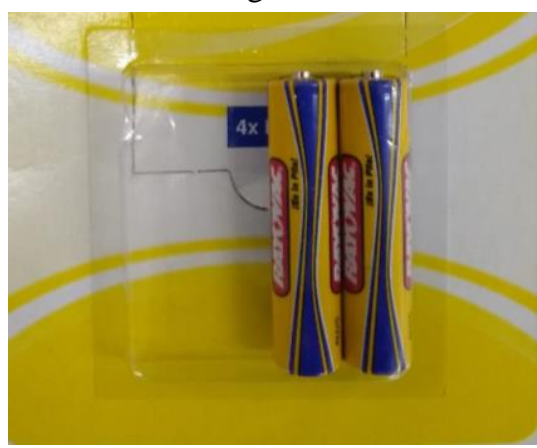

Fonte: Autoria própria (2018) 
A primeira etapa do experimento compreendeu-se através da soldagem do cabo coaxial (Figura 3) na parte inferior do sensor detector de alta tensão (Figura 2). O cabo é revestido de uma camada protetora que faz com que a corrente fique centralizada apenas no fio de cobre que se encontra no centro. $\mathrm{O}$ tamanho do cabo permite que o operador não precise encostar-se ao fio de alta tensão para receber as informações do sensor.

$\mathrm{Na}$ segunda etapa, as pilhas palito (Figura 4) foram inseridas do corpo do sensor, para ativar o seu acionamento. A partir do momento em que as pilhas são inseridas não há necessidade de acionar nenhum botão para que o bastão funcione.

Em seguida, o bastão foi isolado com fita isolante (Figura 1) para dar mais resistência e proteção à ligação do sensor com o cabo coaxial.

Figura 5 - Etapas do processo experimental do bastão detector de alta tensão

Etapa I - Soldagem do cabo coaxial no sensor

\section{Etapa II - Implantação das pilhas do corpo do sensor}

\section{Etapa III - Isolamento da ligação entre o sensor e o cabo}

Fonte: Autoria própria (2018)

\section{Resultados e discussões}

Ao realizar as experiências com o bastão detector de alta tensão, observou-se que ao chegar a certa distância de um objeto eletrizado, sem realizar o toque, o bastão emite sinais sonoros alertando ao usuário que há correntes elétricas. Observou-se que isso é possível porque o cabo coaxial possui uma blindagem que permite detectar mais facilmente a corrente elétrica quando aproximada da região eletrizada.

O equipamento pode ser acoplado no jaleco do funcionário, visando não ser necessário tirar e colocar constantemente, reduzindo assim a chance de esquecimento de uso do mesmo enquanto tiver efetuando as atividades.

Sabendo que o dispositivo possui forma de bastão, vale ressaltar que através de estudos mais aprimorados é possível trazer melhorias para o equipamento, tornando sua funcionalidade ainda mais simplificada, no quesito de uso e aumentar ao máximo a sua precisão. 
A partir do conhecimento de que as funções deste equipamento cumpriram o objetivo esperado, sabemos que terá grande funcionalidade implantada a um EPI já existente no trabalho de um eletricista, diminuindo os riscos de eventuais acidentes de trabalho.

Figura 6 - Bastão detector de alta tensão

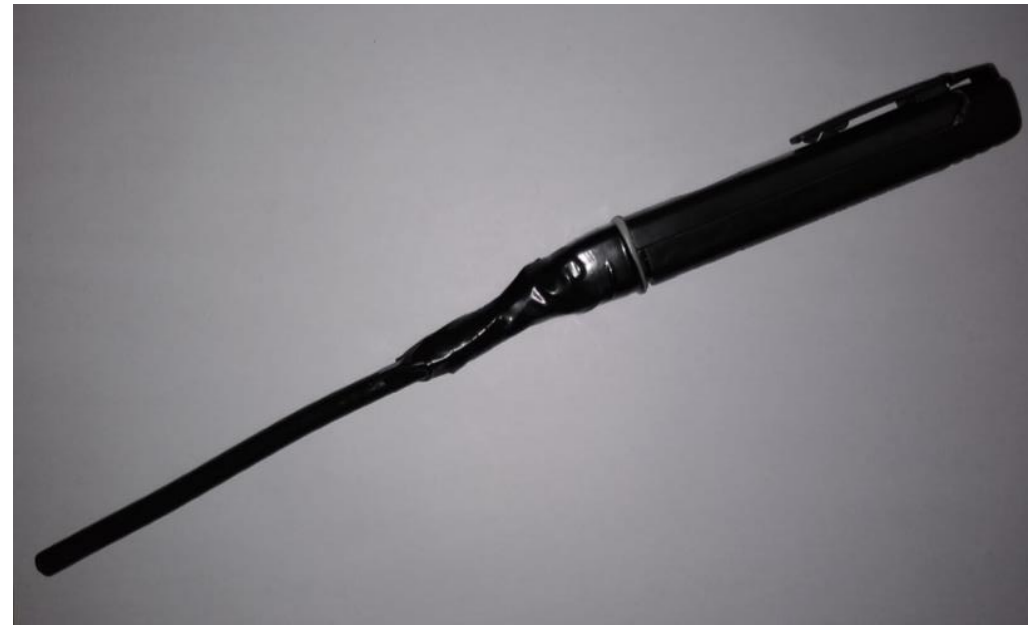

Fonte: Autoria própria (2018)

Figura 7 - Bastão detector de alta tensão

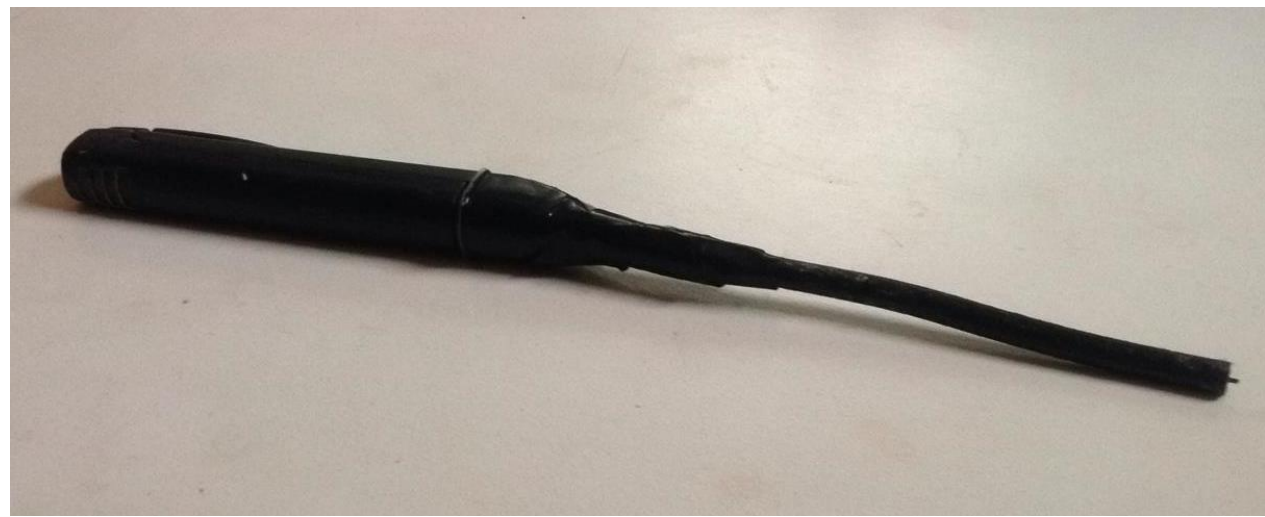

Fonte: Autoria própria (2018)

\section{Considerações finais}

Todos os esforços para a melhoria da eficiência dos EPI's têm como objetivo acompanhar o avanço da tecnologia. A indústria tem a obrigação de estar dentro dos parâmetros normativos para prosseguir o seu funcionamento, por isso a necessidade de investir em equipamentos, em contrapartida esperam que o mesmo seja eficiente as funções atribuídas. 
O bastão desenvolvido tem a função de detectar correntes elétricas através de um sensor sonoro que fornece informações ao usuário antes mesmo de efetuar o toque, diminuindo assim os acidentes com choque elétrico, uma vez que o colaborador não precisará entrar em contato direto com a rede.

A criação desse equipamento se dá como contribuição para empresas que dispõem de serviços com eletricidade ou próximo a ela, visando reduzir as causas de acidentes fatais.

\section{Referências bibliográficas}

Associação Brasileira de Conscientização para os Perigos da Eletricidade (Abracopel). 2018. Dados inéditos sobre acidentes de origem elétrica de 2017. Disponível em: <http:/abracopel.org/noticias/saem-os-dados-ineditos-sobreacidentes-de-origem-eletrica-de-2017/> Acesso em: 05 de Dezembro de 2018.

CAMISASSA, Mara Queiroga. Segurança e saúde no trabalho: NRs 1 a 36 comentadas e descomplicadas / Mara Queiroga Camisassa. - Rio de Janeiro: Forense; São Paulo: Método: 2015.

LOUREIRO, Lucas. Falando de proteção. 2016. Disponível em: <http://falandodeprotecao.com.br/conheca-as5-principais-causas-de-acidente-com-eletricidade/> Acesso em: 22 de Novembro de 2018.

LOURENÇO, Helinton; Elidio de C. Lobão. Análise da Segurança do Trabalho em Serviços com Eletricidade sob a Ótica da Nova NR-10. Disponível em: <http://dalmoro.com.br/images/publications/original/08042010161015.pdf> Acesso em: 04 de Dezembro de 2018.

PEIXOTO, Neverton Hofdtadler. Segurança do trabalho. 2011. Disponível em:

<http://redeetec.mec.gov.br/images/stories/pdf/eixo_ctrl_proc_indust/tec_autom_ind/seg_trab/161012_seg_do_tr ab.pdf> Acesso em: 04 de Dezembro de 2018.

Portaria GM n. ${ }^{\circ}$ 598, de 07 de dezembro de 2004. Disponível em:

<http://trabalho.gov.br/images/Documentos/SST/NR/NR-10-atualizada-2016.pdf> Acesso em: 04 de Dezembro de 2018.

ROZENFELD, H.; FORCELLINI, F.A.; AMARAL, D.C.; TOLEDO, J.C.; SILVA, S.L.; ALLIPRANDINI, D.H.; SCALICE, R.K. Gestão de Desenvolvimento de Produtos: uma referência para a melhoria do processo. São Paulo: Saraiva, 2006.

SILVA, Marcos Pereira. A importância do uso de EPI na prevenção de acidentes de trabalho na indústria madeireira. Disponível em: 〈http://sei-cesucol.edu.br/revista/index.php/facider/article/download/33/77 > Acesso em: 04 de Dezembro de 2018.

TAKAHASHI, S. \& TAKAHASHI, V. P. Gestão de inovação de produtos: estratégia, processo, organização e conhecimento. Rio de Janeiro: Editora Campus, 2007.

TAVEIRA, Susana Andrade. Etapas do Processo de Desenvolvimento de Produto. 2012. Disponível em: $<$ http://dexteradesign.blogspot.com/2012/10/etapas-do-processo-de-desenvolvimento.html> Acesso em: 04 de Dezembro de 2018. 